The International Journal of Indian Psychology

ISSN 2348-5396 (e) | ISSN: 2349-3429 (p)

Volume 4, Issue 1, No. 79, DIP: 18.01.096/20160401

ISBN: 978-1-365-56745-2

http://www.ijip.in | October-December, 2016

\title{
Swadhyaya Scale: An Indian Perspective
}

\author{
Kamlesh $\operatorname{Singh}^{1 *}$, Pooja Sahni ${ }^{2}$
}

\section{ABSTRACT}

Aim of the present paper was to develop a test on Swadhyaya (Self-study) defined in Indian philosophical and religious scriptures. The study was conducted in two phases; 150 participants ( $M=133$ and $F=17)$ with age range=17-54 yrs. $(M=21.43$ yrs., \& $S D=6.79)$ in the pilot study and 491 participants $($ Male $=310 \&$ Female $=181)$ with $18-70$ years age range $(M=32.16$ yrs. \& $\mathrm{SD}=10.92$ ) in the main study. Three factors solution was finalized through exploratory factor analysis; Study of Scriptures, Self-introspection and Self-discipline with $55.74 \%$ of total variance. Scale of Positive and Negative Experiences and Flourishing Scale (SPANE \& FS,Diener et. al., 2010) and Sukha- Dukha scale (Singh, Raina and Sahni, 2016) were used to establish concurrent validity. The scale was found psychometrically robust with high internal consistency $(\alpha=0.79)$ and acceptable concurrent validity as significant positive correlations of Swadhyaya and its factors with Sukha, SPANE-P and FS were obtained.

\section{Keywords: Swadhyaya, Sukha-Dukha, Positive \& Negative Experiences, Flourishing}

In eastern philosophy, Swadhyaya is practiced in many forms. Sometimes it is also understood as the study of scriptures and books. One form of Swadhyaya is mantra meditation, where certain sound or words with meaning are recited, anchoring the mind to one thought (Asara, 2008). This practice helps draw the mind away from outward-going tendencies, silencing the crowding of thoughts, and ultimately towards inward feeling of resonance. It can alternatively be any music, sermon, chant, inspirational book that absorbs the person. In another form it is practiced as a self-reflection process, where one silently meditates in Asana on one's own behaviours, motivations and plans. Self-study is contemplation of one's own motives and behaviors and one's circumstances and the surrounding environment. Such practice provides a direction and keeps us on the right track (Saraswati, 2005). It helps self- introspection - assessing aim and direction of one's life and how desirable changes may lead to a more fulfilling self (Hixon\& Swann, 1993). In this process of reorientation, Swadhyaya appears as self-discipline, such as perseverance, restraint, endurance, thinking before acting and as the ability to carry out one's decisions and plans, in spite of inconvenience, hardships or obstacles. When in practice,

\footnotetext{
${ }^{1}$ Department of Humanities and Social Sciences, Indian Institute of Technology Delhi, India

${ }^{2}$ Department of Humanities and Social Sciences, Indian Institute of Technology Delhi, India

*Responding Author

(C) 2016 K Singh, P Sahni; licensee IJIP. This is an Open Access Research distributed under the terms of the Creative Commons Attribution License (http://creativecommons.org/licenses/by/2.0), which permits unrestricted use, distribution, and reproduction in any Medium, provided the original work is properly cited.
} 


\section{Swadhyaya Scale: An Indian Perspective}

Swadhyaya helps to strengthen self-control, decisiveness and determination. It develops patience and perseverance and helps one get rid of negative habits. This disciplines oneself towards forgoing immediate gratification, to achieve greater and more satisfying goals in the long run (Sasson, 2016; Mischel, Cantor and Feldman, 1996), often defined as self -control- an ability to inhibit or overrule immediate urges to attain a long term goal (Carver \& Scheier, 1981, 1982; De Ridder, Lensvelt-Mulders, Finkenauer, Stok, \& Baumeister, 2012; Metcalfe \& Mischel, 1999; Vohs \& Baumeister, 2004). Such type of self- control is of invaluable importance for well- being (Gillebaart and Ridder, 2015). In line with this notion, many studies have demonstrated that the ability to self-control is vital for human functioning and that it leads to improved work and academic performance, more satisfying relationships, and basically healthier and happier lives (e.g., Duckworth \& Seligman, 2005; Hofmann, Luhmann, Fischer, Vohs, \& Baumeister, 2014; Mischel, Shoda, \&Peake, 1988; Tangney, Baumeister, \& Boone, 2004).

There has been research which shows self - control to be the only one among 32 measured personality variables (e.g., self-esteem, extraversion, energy level) that predicted performance of college students in terms of grade point average (GPA) more robustly than any IQ test scores did. (Wolfe and Johnson, 1996). In a similar study it was found that self-discipline predicted overall academic performance more robustly than did Intelligence test (Duckworth and Seligman, 2005). Self-discipline also correlates positively with self-reported grades, as well as a broad array of personal and interpersonal strengths, (Tangneyet al, 2004)

Further, Self-determination theory (SDT) (Ryan \& Deci 2000) has embraced the concept of eudaimonia, or human flourishing, as a central definitional aspect of well-being. SDT posits that feeling both relatively more positive affect and less negative affect do frequently point to psychological wellness for, as Rogers (1963) suggested, emotional states are indicative of organismic valuation processes. That is, introspection of positive and negative affect is useful in appraisals of the relevance and valence of events and conditions of life with respect to the self. Diener et al (2010) reiterated that human flourishing encompasses purpose in life, relationships, self-esteem, feelings of competence, and optimism. Whereas happiness results from a balance between positive and negative affect also. The inclusion of both general and specific feelings may reflect a wide range of respondents' emotions and feelings regardless of their culture, (Diener et al 2010).

Although in the west, related concepts like self-discipline self- control and self-introspection are widely researched. However there remains a gap to study and understand these concepts and their measures on a broader ambit of Swadhayain the Indian context. In the present paper, we develop a scale to measure Swadhyaya and to study its validity by using various well-being (WB) tests such as sukha - dukha scale based on Indian philosophical/religious WB concept (Singh, Raina and Sahni, 2016), flourishing scale and negative and positive experience scales (Diener et al 2010). It was hypothesized that Swadhyaya and its factors would be positively 


\section{Swadhyaya Scale: An Indian Perspective}

correlated with Sukha, positive experiences and flourishing and negatively correlated with negative experiences and Dukha.

\section{METHOD}

The study was conducted in two phases namely; a pilot study and the main study. The pilot study was further subdivided into four steps namely; (i) item generation, (ii) item review, refinement and modification (iii) assessment of psychometric properties. The main study comprised of item analysis, exploratory factor analysis and concurrent validation of the scale. This methodology ensured that the items retained at the end of the scale were reliable and valid.

\section{PHASE 1: PILOT STUDY}

In this phase, item generation, item review, item refinement, item modification and psychometric properties of the items were studied. Indian philosophical/religious texts describing Swadhyaya was referred along with yogic literature such as Patanjali Yoga Sutras. The various connotations of Swadhyaya like self-study, self-discipline, self-awareness and introspection were also included in the review of literature for item generation.

\section{Item Generation}

On the basis of the extensive review of literature a pool of 22 potential items in Hindi language to find out the extent to which our participants perceive Swadhyaya.

\section{Item Review, Refinement and Modification}

First of all, content validity of the scale was established. Four subject experts reviewed the items in the context of their clarity (Visser, Krosnick, and Lavrakas, 2000), readability level and their relevance for the purpose on a four point rating scale with 1 as "least relevant" to 4 as "most relevant”. Items were screened based on qualitative feedback on content and quantitative scoring with Content validity index CVI > 0.75 (Yaghmaie, 2003). One item was deleted based on this criteria. The item was also perceived to be difficult in understanding by 2 of the experts for an average Hindi speaking population. Thus, the scale comprised of remaining 21 items.

\section{Participants \& Procedure}

One hundred and fifty participants, 17 female (11.3\%) and 133 male (88.7\%) participated in the pilot study. The age range was 17 to 54 years with mean age 21.43 yrs. and SD=6.79. Only 12 participants were working while rest of 138 participants were college going students and 7 participants were married whereas 143 participants were unmarried.

Front page of the questionnaire had questions on demographic information (e.g. age, gender, marital status and occupation) and consent form. Participants were asked to rate the degree to which they experience or practice Swadhyaya in their lives on a 5 point scale from 1 (never) to 5 (always). Data was collected on Hindi speaking population. 


\section{Swadhyaya Scale: An Indian Perspective}

\section{Data Analysis \& Results}

The data were analyzed using SPSS version 17.0. The data were screened to check the minimum (1) and maximum (5) values. SPSS preliminary frequency output was analysed for missing values. Frequency analysis for each item indicated that responses for each domain had minimum and maximum values with the range of $1-5$. The percentage of missing values was under $5 \%$ and random in nature. The missing data was replaced by the series mean method. Then, descriptive analysis and exploratory factor analysis was calculated.

Items were screened for outliers on the basis of mean and standard deviation (SD). For the robustness of the scale a strict criteria of Mean acceptable range 2-4 and SD>1.0 (Jackson 1970) was followed and Swadhyaya items had a mean range of 2.23-3.86 and SD of 1.05-1.55. All the items were also found within limits for skewness and kurtosis ( $\mathrm{Sk}<2.0$, Tabachnick \& Fidell, 1996) and (K<7.0, Finch, 1996). Corrected item-total correlation ranging from $r=0.24$ to 0.69 ( $<0.20$, Kline, 1993) and all Alphas for if-item deleted were high (above $\alpha=.86)$ Thus all items were retained for further analysis at this stage.

Factor Analysis was conducted and the KMO (0.87) and Bartlett Measure of sampling adequacy ( $p<0.01$ ) was found to be very good ( $>0.80$, Field, 2004). Factor analysis was applied with Principal Component Analysis with Varimax rotation. Five factors emerged with $>1$ eigen value which explained $60.43 \%$ of total variance. However, factor solution was not finalized at this stage.

\section{PHASE 2: MAIN STUDY}

The aim of the study was to reassess the psychometric properties and validate the scale with 21 items from pilot study and to explore a final factor solution.

\section{Participants and Procedure}

Five hundred participants were recruited for the study out of which 9 were rejected due to incomplete data. Remaining data of 491 participants from urban and semi urban settings comprised of 181 female and 310 male. Age range was from $18-70$ years $(\mathrm{M}=32.16$ yrs. and $\mathrm{SD}=10.92$ ). $76.7 \%$ participants were married.

A booklet, containing demographic sheet, consent form, newly developed 21 items Swadhyaya scale with selected scales for validation, was used in Hindi for data collection.

\section{Measures used for Swadhyaya scale validation}

Scale of Positive and Negative Experiences (SPANE, Diener et. al., 2010): SPANE is a 12 item scale that is rated on 5 point Likert scale. Singh (2014) has translated the scale in Hindi and found thorough psychometric properties of the Hindi translated version with Cronbach Alpha for 


\section{Swadhyaya Scale: An Indian Perspective}

SPANE P $\alpha=0.69$ and SPANE N $\alpha=0.69$. Alpha Reliability of SPANE P $\alpha=0.87$, SPANE N and $\alpha=0.76$ was found in the current study.

Flourishing Scale (FS; Diener et al., 2010): This is an 8 items scale that provides one factor of the positive human functioning. The scale was found to have acceptable Cronbach's alpha reliability $\alpha=0.87$ (Diener et al. 2010). Singh (2014) has translated the scale in Hindi and found thorough psychometric properties of the Hindi translated version with very good Cronbach and in the present study $\alpha$ was 0.93 .

Sukha- Dukha scale (Singh, Raina and Sahni, 2016): This is a 41 items scale, 19 items for sukha and 22 items for dukha. The scale had very good reliability for sukha $\alpha=0.85$ and dukhax $=0.91$ (Singh, et al 2016).

\section{ANALYSES \& RESULTS}

The data were analyzed using SPSS version 17.0. A preliminary frequency output was analysed for missing values. Frequency analysis for each item showed that responses for each domain had minimum and maximum values with the range of $1-5$. The percentage of missing values was under $5 \%$ and random. The missing data was replaced by the series mean method. A preliminary analysis to check the Mean, SD, Skewness \& Kurtosis values, Corrected item-total correlation and alpha if item deleted of all the swadhyaya scale`s items was done.

Items were screened for outliers on the basis of mean and SD. For the robustness of the scale a strict criteria of SD>1.0 and Mean range 2-4 (Jackson 1970) was followed. Four items were deleted due to less than 1 SD and the remaining items had acceptable range of Mean \& SD (M range $=2.53-3.87$ and SD range $=1.00-1.19$ ). All the items were found within limits for skewness (range $=-0.76$ to 0.19$)(\mathrm{sk}<2.0$, Tabachnick \& Fidell, 1996) and kurtosis (range $=-0.81$ to -.075$)(\mathrm{K}<7.0$, Finch, 1996). Further one item was discarded due to low corrected item-total correlation $(<0.20$, Kline, 1993) and remaining items range was acceptable $(r=0.23$ to 0.60$)$. All Alphas for if-item deleted were high (above $\alpha=.81$ ) and in acceptable range.

The KMO values and Bartlett test for Swadhyaya Scale $(0.85, \mathrm{p}<0.001)$ was very good. Hence, the data were found fit for subsequent factor analyses.

Principal Component Analysis with Varimax rotation was used on remaining 16 items. Initially, four factors emerged with $>1$ eigen value but the fourth factor had only 2 items. Russell (2002) reported that at least three items per factor are required for a factor model to be identified. Therefore, three factor solution was explored. This was accepted as the factor solution showed at least of three items under each factor with all loadings above 0.40 . Consequently, a 3 factor solution was observed to be most suitable, explaining $55.70 \%$ of variance (see table no. 1 for details). 


\section{Swadhyaya Scale: An Indian Perspective}

Table 1: Exploratory Factor Analysis of Swadhyaya Scale

\begin{tabular}{|l|l|l|l|}
\hline Item no. & F1 & F2 & F3 \\
\hline (S2) & .84 & & \\
\hline (S3) & .78 & & \\
\hline (S1) & .77 & & \\
\hline (S4) & .74 & & \\
\hline (S19) & & .79 & \\
\hline (S18) & & .76 & \\
\hline (S20) & & .76 & \\
\hline (S21) & & .68 & \\
\hline (S17) & & .61 & \\
\hline (S5) & & .52 & \\
\hline (S11) & & & .74 \\
\hline (S12) & & & .72 \\
\hline (S10) & & & .70 \\
\hline (S14) & & & .68 \\
\hline (S13) & & & .63 \\
\hline (S16) & & & .47 \\
\hline Eigen value & 4.78 & 2.79 & 1.34 \\
\hline \% of variance & 29.79 & 17.44 & 8.47 \\
\hline
\end{tabular}

Note: Principal Component Analysis with Varimax rotation was used.

Three factors that were emerged are explained as follows:

Study of Scriptures (Factor 1-SS): According to Hindu philosophy, studying and analysing religious scriptures helps in better understanding of the concept of God. It helps knowing the self. This sub factor consisted of 4 items, like Reflecting on the teachings, reading and following spiritual teachings, agreeing on the spiritual texts lead to strong mental state. The eigenvalue was 4.78 and it explained $29.89 \%$ age of variance.

Introspection (Factor 2 - IS): Introspection refers the examination of one's own conscious thoughts and feelings. It also refers to relating one's experiences to actions. It activates spirituality and ultimately disassociation from negativity. In psychology the process of introspection relies exclusively on observation of one's mental state, while in a spiritual context it may refer to the examination of one's inner self. The factor consisted of 6 items. The eigenvalue was 2.79 and it explained $17.44 \%$ age of variance.

Self - discipline (Factor 3- SD): Contrary to common belief, self-discipline does not mean being harsh toward yourself, or living a limited, restrictive lifestyle. Self-discipline means self-control, which is a sign of inner strength and control of yourself, your actions, and your reactions. It leads to a determined, steady and regular approach towards achieving goals. The factor consisted of 6 items. The eigenvalue was 1.35 and it explained 8.47 \%age of variance.

(C) The International Journal of Indian Psychology, ISSN 2348-5396 (e)| ISSN: 2349-3429 (p) | 158 


\section{Swadhyaya Scale: An Indian Perspective}

\section{Reliability and Concurrent Validity}

The concurrent validity was established by correlating Swadhyaya scale and its factors with Sukha, Dukha, Flourishing, SPANE P and SPANE N as validating domains. The results showed significant correlation supporting our hypothesis as Swadhyaya and its sub-factors being positively correlated with Sukha, flourishing and SPANE P (positive experiences) however correlation with Dukha and SPANE N (negative experiences) were insignificant. The Scale reliability was very good for the Swadhyaya and its dimensions $(\alpha=0.78$ to 85 ), (see table no 2 for details).

Table 2: Correlation between Swadhyaya scale \& its factors with validating scales

\begin{tabular}{|l|l|l|l|l|l|l|l|l|l|}
\hline & Sukha & Dukha & SPANEP & SPANEN & FS & F1 & F2 & F3 & Swadhyaya \\
\hline Sukha & $\mathbf{( 0 . 8 6 )}$ & & & & & & & & \\
\hline Dukha & $-.33^{* *}$ & $\mathbf{( 0 . 9 1 )}$ & & & & & & & \\
\hline SPANE P & $.63^{* *}$ & $-.44^{* *}$ & $\mathbf{( 0 . 8 7 )}$ & & & & & & \\
\hline SPANE N & $-.29^{* *}$ & $.68^{* *}$ & $-.41^{* *}$ & $\mathbf{( 0 . 7 6 )}$ & & & & & \\
\hline FS & $.54^{* *}$ & $-.36^{* *}$ & $.60^{* *}$ & $-.31^{* *}$ & $\mathbf{( 0 . 9 3 )}$ & & & & \\
\hline SS (F1) & $.20^{* *}$ & -.07 & $.16^{* *}$ & .04 & $.21^{* *}$ & $\mathbf{( 0 . 8 5 )}$ & & & \\
\hline IS (F2) & $.33^{* *}$ & -.07 & $.35^{* *}$ & -.06 & $.46^{* *}$ & $.25^{* *}$ & $\mathbf{( 0 . 7 8 )}$ & & \\
\hline SD (F3) & $.19^{* *}$ & .06 & $.18^{* *}$ & .04 & .07 & $.43^{* *}$ & $.15^{* *}$ & $\mathbf{( 0 . 7 9 )}$ & \\
\hline Swadhyaya & $.34^{* *}$ & -.01 & $.34^{* *}$ & .00 & $.34^{* *}$ & $.57^{* *}$ & $.71^{* *}$ & $.79^{* *}$ & $\mathbf{( 0 . 8 0 )}$ \\
\hline
\end{tabular}

** Correlation is significant at the 0.01 level (2-tailed). Swadhyaya factors-F1-F3; Study of Scriptures (SS), Self-introspection (IS) and Self-discipline (SD). Cronbach alphas for the scales/sub-scales displayed across the diagonal in bold italics.

\section{DISCUSSION}

The main purpose of the study was to construct a scale to measure Swadhyaya as defined by Indian philosophical/religious texts. It adds to the growing research literature on indigenous Indian concepts like Triguna (Misra, Suvasini, and Srivastava, 2000; Murthy and Kumar, 2007; Khanna, Singh, Singla and Verma, 2013), Sat-chit-anand (Singh, Khari, Amonkar, Arya and Kasav, 2013), Anasakti(Singh \&Raina, 2015; Bhushan and Jha, 2005; Banth and Talwar, 2012), SukhaandDukha (Singh, Raina\&Sahni, 2016) etc. The psychometric properties showed that the test is reliable and a valid measure. Earlier researches (Singh, Misra and Raad, 2013) have emphasized the importance of the vernacular language in the study of psychological variables. More so in Indian context where over 41 \% of population speak Hindi as per census 2001. Therefore, the scale has been developed in Hindi first.

All retained items of the scale have acceptable descriptive statistics like Mean range, SD, skewness, kurtosis, corrected Item- total correlations (CIT) and alphas if item deleted. 


\section{Swadhyaya Scale: An Indian Perspective}

The empirical structure of final scale that emerged consisted of 16 items, with a three factor structure explaining $55.70 \%$ of variance. It was found to be both psychometrically sound and most proximal to the conceptual framework. All factor loadings of retained items were greater than 0.40. For interpretive purposes cut-off point of loadings of 0.40 or higher is suggested (Stevens, 2002). The factor structure was in line with the Indian philosophy that views Swadhyayanot only as study of scriptures but as a niyama - an approach of achieving a state of introspection, self-discipline, self-control, self -determination and ultimately self- awareness. Correlations between the validating scales and Swadhyayascale and its factors further validated the scale. The present study findings suggested that Swadhyaya was positively associated with positive facets of WB, however it was not associated with negative facets of WB.The overall scale exhibits high internal consistency $(a=0.80)$.

Thus this study makes theoretical contributions towards enriching the meaning of self- study, self- discipline, self-introspection, self- awareness and well-being in the Indian context. The theory may enhance the understanding and importance of Swadhyaya. Conceptualization of Swadhyaya and its measure was an attempt to synergize Indian concepts with main stream of psychology. The empirical validation reduces the data-theory disconnect, providing it robustness and scope for testing across cultures.

\section{LIMITATIONS AND FUTURE SCOPE}

The present study established psychometric properties of Swadhyaya scale by exploratory factor analysis. It can be confirmed further through confirmatory factor analysis. T resultant model can still be tested on a wider population. The role of demographic variables such as gender, age, religion can also be studied. Lastly, Scale may be translated in other languages for its broader use.

\section{Acknowledgments}

The author appreciates all those who participated in the study and helped to facilitate the research process.

\section{Conflict of Interests}

The author declared no conflict of interests.

\section{REFERENCES}

Āśara, B. (2008). Svādhyāya: Vivecanagrantha. Rājakoṭa: BipinaĀśara.

Banth, S., \&Talwar, C. (2012). Anasakti, the Hindu ideal, and its relationship to well-being and orientations to happiness. Journal of religion and health, 51(3), 934-946.

Bhushan, L. I., \&Jha, M. K. (2005). Developing the test of Asakti-Anasakti. Indian Journal of Psychometry and Education,36(1), 3-9.

Carver, C. S., \& Scheier, M. F. (1981). Attention and Self-Regulation. A control theory approach to human behavior. New York: Springer Verlag 


\section{Swadhyaya Scale: An Indian Perspective}

Diener, E., Wirtz, D., Tov, W., Kim-Prieto, C., Choi, D. W., Oishi, S., \& Biswas-Diener, R. (2010). New well-being measures: Short scales to assess flourishing and positive and negative feelings. Social Indicators Research,97(2), 143-156.

Duckworth, A. L., \& Seligman, M. E. (2005, 12). Self-Discipline Outdoes IQ in Predicting Academic Performance of Adolescents. Psychological Science, 16(12), 939-944.

Field, A. (2005). Discovering Statistics Using SPSS (2nd ed.). London, UK: Sage

Gillebaart, M., \& Ridder, D. T. (2015). Effortless Self-Control: A Novel Perspective on Response Conflict Strategies in Trait Self-Control. Social and Personality Psychology Compass, 9(2), 88-99.

Hixon, J. G., \& Swann, W. B. (1993). When does introspection bear fruit? Self-reflection, selfinsight, and interpersonal choices. Journal of Personality and Social Psychology, 64(1), 35-43.

Hofmann, W., Fisher, R. R., Luhmann, M., Vohs, K. D., \& Baumeister, R. F. (2014). Yes, but are they happy? Effects of trait self-control on affective well-being and life satisfaction. Journal of Personality, 82, 265-277.

Jackson, D. N. (1970). A sequential system for personality scale development. Current topics in clinical and community psychology, 2, 61-96.

Khanna, P., Singh, K., Singla, S., \&Verma, V. (2013). Relationship between Triguna theory and well-being indicators. International Journal of Yoga-Philosophy, Psychology and Parapsychology,1(2), 69-74.

Kline, P. (1993). The Handbook of Psychological Testing. London, UK: Routledge.

Likert, R. (1932). A technique for the measurement of attitudes. Archives of psychology, 140.

Metcalfe, J., \& Mischel, W. (1999). A hot/cool-system analysis of delay of gratification: Dynamics of willpower. Psychological Review,106(1), 3-19.

Mischel, W., Cantor, N., \& Feldman, S. (1996). Principles of self-regulation: The nature of willpower and self-control. In Social psychology: Handbook of basic principles, (pp. 329360). Guilford Press: New York, NY, US.

Mischel, W., Shoda, Y., \&Peake, P. K. (1988). The nature of adolescent competencies predicted by preschool delay of gratification. Journal of Personality and Social Psychology,54(4), 687-696.

Misra, G., Suvasini, C., \& Srivastava, A. K. (2000). Psychology of wisdom: Western and Eastern perspectives. Journal of Indian Psychology, 18(1), 1-32

Ridder, D. T., Lensvelt-Mulders, G., Finkenauer, C., Stok, F. M., \& Baumeister, R. F. (2011). Taking Stock of Self-Control: A Meta-Analysis of How Trait Self-Control Relates to a Wide Range of Behaviors. Personality and Social Psychology Review,16(1), 76-99.

Russell, D. W. (2002). In search of underlying dimensions: The use (and abuse) of factor analysis in Personality and Social Psychology Bulletin. Personality and social psychology bulletin,28(12), 1629-1646.

Ryan, R. M., \& Deci, E. L. (2001). On Happiness and Human Potentials: A Review of Research on Hedonic and Eudaimonic Well-Being. Annual Review of Psychology Annu. Rev. Psychol., 52(1), 141-166. 


\section{Swadhyaya Scale: An Indian Perspective}

Saraswati, Bhaktisiddhanta (2005). Brill's Encyclopedia of Hinduism. doi:10.1163/ 12345678_beh_com_9000000229

Sasson, B.R, (2016). Strengthen your Will power and Self Discipline, Retrieved from http://www.successconsciousness.com

Singh, J. K., Misra, G., \& De Raad, B. (2013). Personality structure in the trait lexicon of Hindi, a major language spoken in India. European Journal of Personality,27(6), 605-620.

Singh, K. (2014). Relationship of Demographic Variables, Socio-Cultural Issues and Selected Psychological Constructs with the Positive Mental Health of North Indian Adolescents, ICMR Project Report (RP02586).

Singh, K., \& Raina, M. (2015). Development and validation of a test on Anasakti (nonattachment): An Indian model of well-being. Mental Health, Religion \& Culture, 18(9), 715-725

Singh, K., Khari, C., Amonkar, R. S., Arya, N. K., \&Kasav, S. (2013). Development and validation of a new scale: Sat-Chit-Ananda Scale. International Journal on Vedic Foundations of Management, 1(2), 102-122.

Singh, K., Raina, M., \&Sahni, P. (2016). The Concept and Measure of Sukha-Dukha: An Indian Perspective on Well-Being. Journal of Spirituality in Mental Health, 1-17.

Stevens, J. P. (2012). Applied multivariate statistics for the social sciences. New York, NY: Routledge.

Tabachnick, B. G., \&Fidell, L. S. (2007). Using multivariate statistics. Boston: Pearson/Allyn\& Bacon.

Tangney, J. P., Baumeister, R. F., \& Boone, A. L. (2004). High Self-Control Predicts Good Adjustment, Less Pathology, Better Grades, and Interpersonal Success. Journal of Personality, 72(2), 271-324.

Visser, P. S., Krosnick, J. A., \& Lavrakas, P. J. (2000). Survey research. In H. T. Reis \& C. M. Judd (Eds.), Handbook of research methods in social and personality psychology (pp. 223-252). New York, NY: Cambridge University Press.

Vohs, K. D., \& Baumeister, R. F. (2004). Self-Control. Encyclopedia of Applied Psychology, 369-373.

Wolfe, R. N., \& Johnson, S. D. (1995). Personality as a Predictor of College Performance. Educational and Psychological Measurement, 55(2), 177-185.

Yaghmaie, F. (2003). Content validity and its estimation. Journal of Medical Education,3, 25-27.

How to cite this article: K Singh, P Sahni (2016), Swadhyaya Scale: An Indian Perspective, International Journal of Indian Psychology, Volume 4, Issue 1, No. 79, ISSN:2348-5396 (e), ISSN:2349-3429 (p), DIP:18.01.096/20160304, ISBN:978-1-365-56745-2 